\title{
Free, soluble interleukin-17 protein during severe inflammation in human airways
}

\author{
M. Laan*, L. Palmberg\#, K. Larsson*, A. Lindén*
}

Free, soluble interleukin-17 protein during severe inflammation in human airways. M. Laan, L. Palmberg, K. Larsson, A. Lindén. C ERS Journals Ltd 2002.

ABSTRACT: Studies in rodents indicate that the cytokine, interleukin (IL)-17, links the activation of T-lymphocytes to neutrophilic inflammation. The aim of the current study was to determine whether free, soluble IL-17 protein can be released during severe inflammation in human airways.

Fifteen healthy subjects were exposed to a swine confinement in order to induce severe inflammation characterized by high neutrophil numbers in the airways. Bronchoalveolar lavage (BAL) fluid was harvested 2 weeks prior to and $24 \mathrm{~h}$ after this exposure and the concentration of IL-17 protein was measured using an enzymelinked immunosorbent assay. Total and cell differential counts were also performed in BAL fluid.

Prior to exposure to the swine confinement, the concentration of IL-17 in BAL fluid was low $\left(<7.8 \mathrm{pg} \cdot \mathrm{mL}^{-1}\right)$ in 14 out of 15 subjects. However, exposure to the swine confinement caused an increase in IL-17 in 13 out of 15 subjects (median IL-17 concentration of $26.9 \mathrm{pg} \cdot \mathrm{mL}^{-1}$ ). This exposure also caused a 51-fold increase in the concentration of neutrophils in BAL fluid.

To conclude, free, soluble interleukin-17 protein can be released during severe inflammation characterized by high neutrophil numbers in human airways. The significance of interleukin-17 in inflammatory airway diseases therefore deserves further evaluation.

Eur Respir J 2002; 19: 534-537.
*Lung Pharmacology Group, Dept of Respiratory Medicine and Allergology, Göteborg University, Gothenburg and ${ }^{\#}$ Program for Respiratory Health and Climate, National Institute for Working Life, Solna, Sweden.

Correspondence: A. Lindén, Lung Pharmacology Group, Göteborg University, Guldhedsgatan 10A, S-413 46 Gothenburg, Sweden

Fax: 4631413290

E-mail: anders.linden@lungall.gu.se

Keywords: Cytokine, human airway, interleukin-17, neutrophil, organic dust, swine confinement

Received: September 172001 Accepted after revision November 23 2001

The present study was funded by Göteborg University, the Swedish Heart Lung Foundation, the Swedish Medical Research Council (K200071X-09048-11A), the Vårdal Foundation and Glaxo Wellcome, Sweden.
The recruitment and activation of neutrophils in the airways constitutes a hallmark of chronic bronchitis and chronic obstructive pulmonary disease [1]. Neutrophils are also present and activated in the airways during acute, severe exacerbations of bronchial asthma $[1,2]$. For these inflammatory airway diseases, there is now evidence that the activated neutrophils may contribute to bronchial hyperresponsiveness, epithelial damage, hypersecretion and tissue remodelling, by releasing proteolytic enzymes and free oxygen radicals [1-5]. However, the mechanisms leading to this recruitment and activation of neutrophils are not fully understood.

As indicated in rodent airways in vivo, the recruitment of neutrophils into the airways can be controlled by activated T-lymphocytes under certain conditions [6-8]. Recent studies on rodents in vivo suggest that the cytokine interleukin (IL)-17 links the activation of certain T-lymphocytes to neutrophil recruitment in the airways [1]. It is possible that IL-17 causes neutrophil recruitment and activation by inducing production of neutrophil-mobilizing cytokines, such as IL-6 and IL-8, released from bronchial epithelial and other airway cells [9-11]. However, it is not known whether free, soluble IL-17 protein can actually be released in human airways during severe inflammation, characterized by high neutrophil numbers.

The authors hypothesized that endogenous IL-17 can be released in human airways as a free, soluble protein during severe inflammation involving lymphocytes and neutrophils in vivo. To evaluate this hypothesis, bronchoalveolar lavage (BAL) fluid was harvested from healthy, nonsmoking volunteers prior to and after exposure to a swine confinement, and the concentration of free, soluble IL-17 protein was determined. Previous studies show that this type of exposure causes recruitment of neutrophils and lymphocytes and increases the concentrations of neutrophil-mobilizing cytokines, such as IL-6, IL-8 and tumour necrosis factor (TNF)- $\alpha$ in the airways [12-14].

\section{Material and methods}

\section{Study design}

The study protocol was approved by the Ethics Committee at Karolinska Institute. Fifteen clinicallyhealthy, nonsmoking volunteers of both sexes gave 
informed consent to participate in the study. All the subjects were nonatopic and nonasthmatic as determined by history and a questionnaire. These subjects were exposed to a swine dust confinement for $3 \mathrm{~h}$ while assisting a farmer weighing pigs in a swine confinement with $\sim 900$ pigs, as described previously [12-14]. This procedure is known to aerosolize organic dust; exposure was assessed as described previously [12-14]. A normal lung function at baseline was ascertained by conducting spirometry (as described later) in all subjects prior to the first BAL and 2 weeks prior to exposure to a swine confinement. At this time point, it was also ascertained that no subject displayed airway hyperresponsiveness, by conducting methacholine provocation. BAL (see later) was performed 2 weeks prior to (baseline) and $24 \mathrm{~h}$ after the start of exposure to a swine confinement.

\section{Lung function}

Spirometry was performed in accordance with the criteria of the American Thoracic Society using a low-resistance rolling-seal spirometer (OHIO model 840; Airco, Madison, WI, USA) [15]. The reference values by Hedenstrom and co-workers were used $[16,17]$.

\section{Bronchial responsiveness}

The methacholine provocation test was conducted in a standardized manner as described previously [18]. Briefly, inhalation of the diluent (placebo) was followed by inhalation of doubling concentrations of methacholine starting at $0.5 \mathrm{mg} \cdot \mathrm{mL}^{-1}$. The challenge was stopped either at a forced expiratory volume in one second (FEV1) decrease of $20 \%$, compared to the value obtained after inhalation of diluent, or after inhalation of the highest methacholine concentration $\left(64 \mathrm{mg} \cdot \mathrm{mL}^{-1}\right)$. The cumulative dose causing a $20 \%$ decrease in FEV1 (PD20) was calculated.

\section{Bronchoalveolar lavage}

Bronchoscopy and BAL were performed according to standard procedures as described previously $[18,19]$. Briefly, after premedication with morphinescopolamine, a flexible fibreoptic bronchoscope (Olympus Type 4B2; Olympus Optical Co. Ltd, Shinjukuku, Tokyo, Japan) was inserted through the mouth or the nose under local anaesthesia with

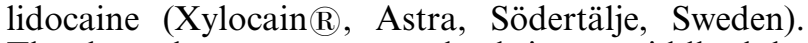
The bronchoscope was wedged in a middle lobe subsegmental bronchus and $250 \mathrm{~mL}$ of sterile saline at $37^{\circ} \mathrm{C}$ was instilled in five aliquots of $50 \mathrm{~mL}$. After each installation, the BAL suspension was gently aspirated and collected in a siliconized plastic bottle kept on ice.

After filtering through a single layer of gauze, the BAL suspension was centrifuged at $200 \times g$ for $10 \mathrm{~min}$ at $4{ }^{\circ} \mathrm{C}$. The cell-free supernatant was kept frozen at $-70^{\circ} \mathrm{C}$ until analysis. The cell pellet was resuspended in Tris-Hanks balanced salt solution at $\mathrm{pH} 7.4$ and the total cell number (i.e. concentration) was determined for each sample in a Bürkner chamber. Differential cell counts were performed by flow cytometry (Epics Profile II; Coulter Electronics Inc., Hialeah, FL, USA). The samples were prepared in the Coulter Q-PREP $\mathbb{R}$, and incubated for $10 \mathrm{~min}$ with CD14-CD45 monoclonal antibodies (Mo2-RD1/Kc56-Fitc; Cyto-Stat/ Coulter Clone, Coulter Corp., Miami, FL, USA).

\section{Analyses of bronchoalveolar lavage fluid}

For IL-17 protein measurements, cell-free BAL fluid was concentrated 200 times using ultrafiltration

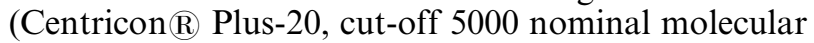
weight limits; Millipore, Bedford, MA, USA) according to the manufacturer's instructions. The IL-17 concentration was determined using a commercial IL-17 enzyme-linked immunosorbent assay (ELISA) kit (R\&D Systems Europe, Abington, UK). Concentrations below the detection limit of the ELISA were assigned a value of $3.9 \mathrm{pg} \cdot \mathrm{mL}^{-1}$ (the mean of zero and the lowest IL-17 standard of the ELISA). The concentrations of IL- 6 , IL- 8 and TNF- $\alpha$ were determined in unconcentrated, cell-free BAL fluid using commercial ELISA for IL-6, IL-8 and TNF- $\alpha$, respectively (all from R\&D Systems Europe).

\section{Data analysis}

All results are presented as median (range) values unless otherwise stated. Only nonparametric tests were utilized. The Wilcoxon signed rank test was used for comparisons between two dependent groups and the Spearman rank correlation for detecting a relationship between two variables. A p-value $<0.05$ was considered as statistically significant.

\section{Results}

\section{Clinical baseline characteristics}

Nine males and six females with a median (range) age of $26(22-46)$ yrs were included in the study. These subjects displayed an FEV1 of $100(71-126) \%$ predicted and a vital capacity of $95(75-111) \%$ pred. The included subjects displayed a median PD20 value for methacholine of 2.35 (0.66-64.00).

\section{Exposure to a swine confinement}

For the exposures conducted in this study, the median (range) total dust and endotoxin content per $\mathrm{m}^{3}$ air was $24(14-43) \mathrm{mg}$ and $1.2(0.3-1.5) \mu \mathrm{g}$, respectively.

\section{Interleukin-17 in bronchoalveolar lavage fluid}

Exposure to a swine dust confinement caused no pronounced change in BAL recovery volume; the recovery volume was $195(145-220) \mathrm{mL}$ prior to and $188(162-203) \mathrm{mL}$ after exposure. Prior to this 


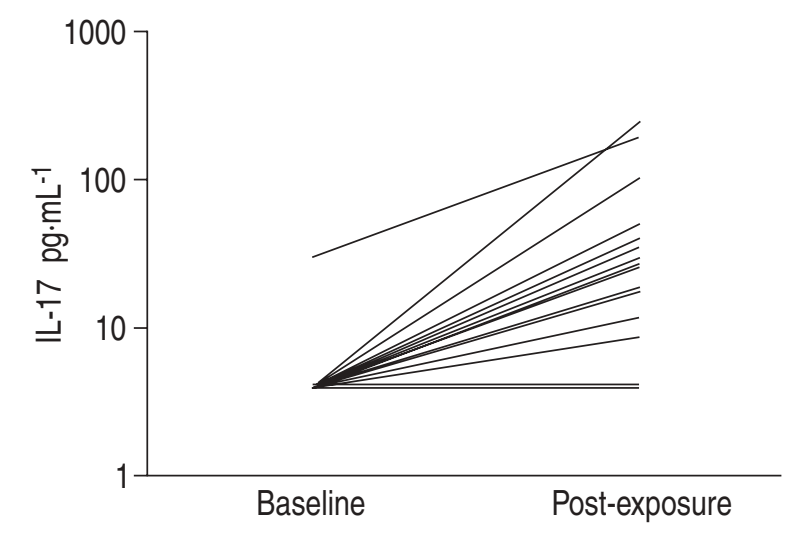

Fig. 1.-Effect of 3-h exposure to a swine confinement on the concentration of free, soluble interleukin (IL)-17 protein in bronchoalveolar lavage fluid (cell-free, concentrated 200×) harvested $24 \mathrm{~h}$ after exposure from 15 healthy volunteers and measured using an enzyme-linked immunosorbent assay. Data are presented as individual IL-17 concentrations (log scale) prior to (baseline) and after exposure (post-exposure) to the swine confinement. After exposure, the median concentration of IL-17 was 26.9 (3.9-247.4) $\mathrm{pg} \cdot \mathrm{mL}^{-1}$ and this increase was statistically significant $(\mathrm{p}<0.005)$

exposure, 14 out of 15 subjects displayed nondetectable concentration $\left(<7.8 \mathrm{pg} \cdot \mathrm{mL}^{-1}\right)$ of IL-17 protein in BAL fluid. Exposure to a swine confinement significantly increased the IL-17 concentration in 13 out of 15 subjects (fig. 1).

\section{Number of inflammatory cells in bronchoalveolar lavage fluid}

Exposure to the swine confinement caused a 51-fold increase in BAL neutrophils and a 2-3-fold increase in BAL lymphocytes and macrophages (table 1). There was no correlation between the level of IL-17 protein in BAL fluid and the concentration of BAL neutrophils after exposure to the swine confinement (data not shown).

\section{Levels of interleukin-6, -8 and tumour necrosis factor- $\alpha$ in bronchoalveolar lavage fluid}

Exposure to the swine confinement caused a statistically significant (Wilcoxon signed rank test:

Table 1.-Total cell concentration of all cells, total cells, neutrophils, lymphocytes and macrophages, in bronchoalveolar lavage fluid from 15 healthy human subjects, prior to (baseline) and $24 \mathrm{~h}$ after (post-exposure) a 3-h exposure to swine confinement

\begin{tabular}{lcc}
\hline & Baseline & Post-exposure \\
\hline Total cells & $44.1(17.4-130.2)$ & $210.3(34.8-689.0)^{\#}$ \\
Neutrophils & $1.2(0.4-3.7)$ & $61.5(7.3-256.2)^{\#}$ \\
Lymphocytes & $12.2(4.3-52.0)$ & $33.7(10.8-232.9)^{\#}$ \\
Macrophages & $28.1(12.2-95.5)$ & $82.0(15.5-219.1)^{\#}$ \\
\hline
\end{tabular}

Data are presented as $1 \times 10^{6} \cdot \mathrm{L}^{-1}$ median (range). ${ }^{\#}: \mathrm{p}<0.005$, compared with cell number prior to exposure. $\mathrm{p}<0.005, \mathrm{n}=15$ ) increase in IL-6 (from $1.3(0.2-2.5)$ to 32.4 (6.7-187.2)), IL-8 (from $<31.3(<31.3-191.1)$ to $99.5(42.3-431.1))$ and TNF- $\alpha$ (from $0.5(<0.25-2.4)$ to $4.0(0.5-16.6))$ in cell-free BAL fluid. However, in spite of visual trends, there was no statistically significant correlation between the concentration of IL-17 and that of IL-6, IL-8 or TNF- $\alpha$ (fig. 2).
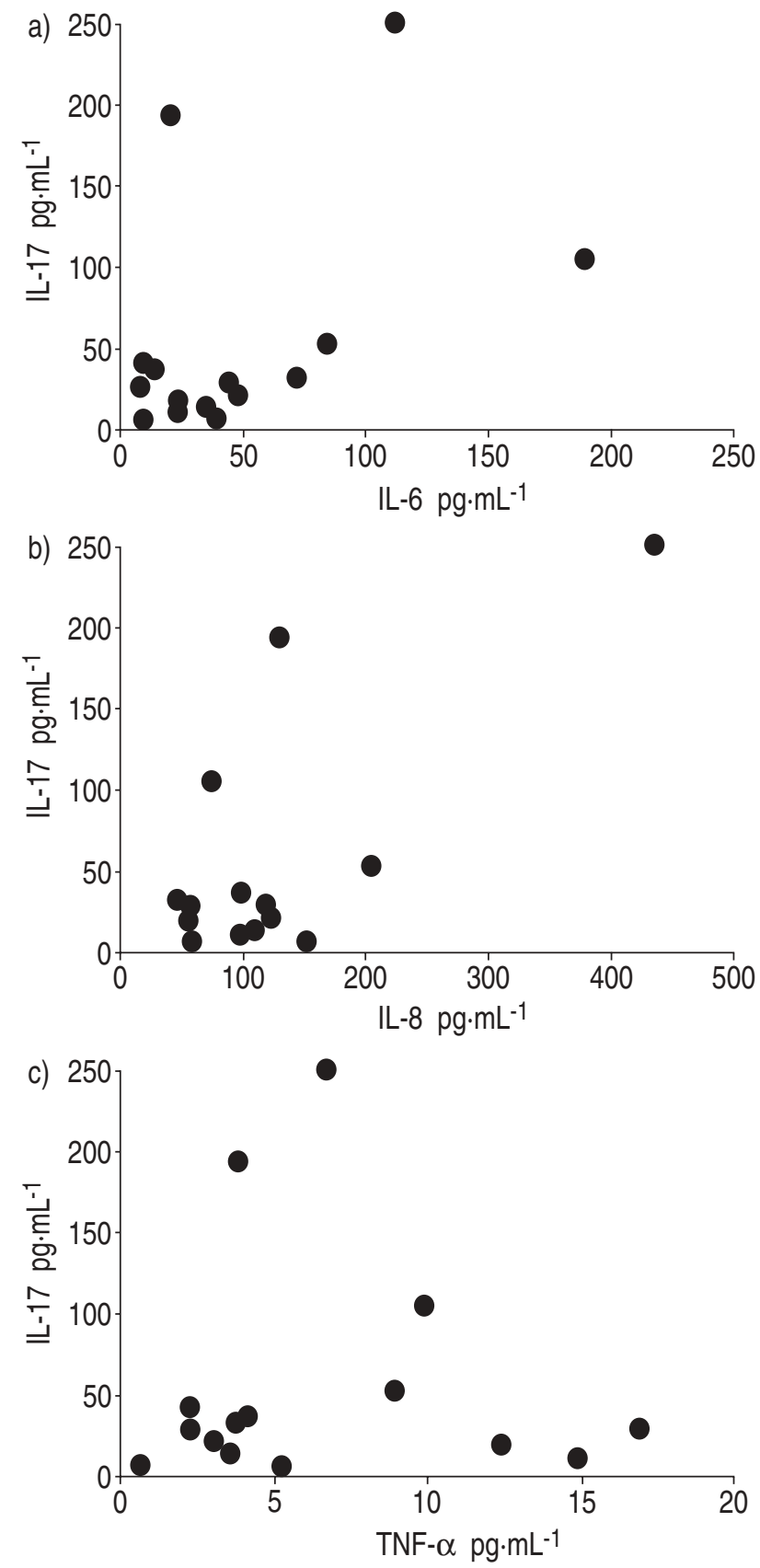

Fig. 2. - Scattergrams showing individual concentrations of interleukin (IL)-17 protein versus a) IL-6, b) IL-8 and c) tumour necrosis factor (TNF)- $\alpha$ protein in cell-free bronchoalveolar lavage fluid harvested from previously-healthy human volunteers, $24 \mathrm{~h}$ after exposure to a swine confinement, measured using enzymelinked immunosorbent assay. There was no statistically significant correlation between IL-17 and IL- $6(\mathrm{rho}=0.4, \mathrm{p}=0.2, \mathrm{n}=15)$; IL-8 $(\mathrm{rho}=0.3, \mathrm{p}=0.3, \mathrm{n}=14)$; or TNF- $\alpha(\mathrm{rho}=0.1, \mathrm{p}=0.6, \mathrm{n}=15)$. 


\section{Discussion}

The current study was conducted on nonsmoking, clinically-healthy subjects with normal or close-tonormal lung function and airway reactivity, prior to exposure to a swine confinement. The results show that in these subjects, exposure to a swine confinement causes a substantial increase in free, soluble IL-17 protein in association with severe inflammation in the airways. This induced inflammation is characterized by high numbers of neutrophils and lymphocytes in the airways. This study also shows that in the majority of clinically-healthy subjects, the level of IL-17 protein is very low $\left(<7.8 \mathrm{pg} \cdot \mathrm{mL}^{-1}\right)$ prior to induced airway inflammation. Thus, IL-17 is released in human airways during severe inflammation characterized by recruitment of neutrophils and lymphocytes. As indicated by previous studies, this IL-17 may originate from CD4+ and CD8+ subsets of T-lymphocytes, cells that can become activated by organic dust $[1,19]$.

The present study also shows that exposure to a swine dust confinement causes a significant increase in the airway level of the neutrophil-mobilizing cytokines IL-6, IL- 8 and TNF- $\alpha$; associated with the increase in airway neutrophils and lymphocytes, in line with previous studies [14-18]. Indeed, these findings complement the previous mechanistic studies on the effects of IL-17 in the airways [1]. The authors found visual trends suggesting a correlation between IL-17 on one hand, and IL-6 and IL-8, respectively, on the other, but they were unable to confirm a statistically significant correlation for these neutrophil-mobilizing cytokines. The same was true for IL-17 and the concentration of airway neutrophils. This lack of a statistically significant correlation $24 \mathrm{~h}$ after exposure to a swine confinement is not surprising, because the initial, induced increase in IL-17 is probably causing a subsequent increase in neutrophil-mobilizing cytokines several hours later, in turn, followed by neutrophil recruitment several hours after that. All these events are likely to peak at different timepoints. Thus, in view of the current findings, future studies on IL-17 in human airways should also analyse BAL fluid harvested at earlier timepoints after the initial stimulation of IL-17 release. In doing so, the order of inflammatory events could be clarified in detail.

In conclusion, this study demonstrates that the T-cell cytokine interleukin-17 is released as a free, soluble protein during severe inflammation, characterized by high neutrophil numbers in human airways. This fact calls for further investigation of interleukin17 in conditions characterized by neutrophilic inflammation, such as chronic obstructive pulmonary disease and acute, severe exacerbations of asthma.

\section{References}

1. Lindén A, Hoshino H, Laan M. Airway neutrophilia and interleukin-17. Eur Respir J 2000; 15: 973-977.

2. Ordonez C, Shaughnessy T, Matthay M, Fahy JV. Increased neutrophil numbers and IL-8 levels in airway secretions in acute severe asthma. Am J Crit Care Med 2000; 161: 1185-1190.
3. Weinberg KS, Hayes JA. Elastase-induced emphysema: asynchronous bronchial, alveolar and endothelial cell proliferation during the acute response to injury. J Pathol 1982; 136: 253-264.

4. Venaille TJ, Mendis AH, Phillips MJ, Thompson PJ, Robinson BW. Role of neutrophils in mediating human epithelial cell detachment from native basement membrane. J Allergy Clin Immunol 1995; 95: 597-606.

5. Matsumoto K, Aizawa $\mathrm{H}$, Inoue $\mathrm{H}$, Koto $\mathrm{H}$, Nakaro $\mathrm{H}$, Hara N. Role of neutrophil elastase in ozoneinduced airway responses in guinea-pigs. Eur Respir $J$ 1999; 14: 1088-1094.

6. Gavett SH, Chen X, Finkelman F, Wills-Karp M. Depletion of murine CD4+ T lymphocytes prevents antigen-induced airway hyperreactivity and pulmonary eosinophilia. Am J Respir Cell Mol Biol 1994; 10: $587-593$.

7. Nakajima H, Iwamoto I, Tomoe S, et al. CD4+ T-lymphocytes and interleukin-5 mediate antigeninduced eosinophil infiltration into the mouse trachea. Am Rev Respir Dis 1992; 146: 374-377.

8. Renzi PM, Yang JP, Diamantstein T, Martin JG. Effects of depeletion of cells bearing the interleukin-2 receptor on immunoglobulin production and allergic airway responses in the rat. Am J Respir Crit Care Med 1996; 153: 1214-1221.

9. Laan M, Lötvall J, Chung K, Lindén A. IL-17induced cytokine release in human bronchial epithelial cells in vitro: role of mitogen-activated protein (MAP) kinases. Br J Pharmacol 2001; 133: 200-206.

10. Richman-Eisenstat JB, Jorens PG, Hebert CA, Ueki I, Nadel JA. Interleukin-8: an important chemoattractant in sputum of patients with chronic inflammatory airway diseases. Am J Physiol 1993; 264: L413-L418.

11. Bank U, Reinhold D, Kunz D, et al. Effects of interleukin-6 (IL-6) and transforming growth factorbeta (TGF-beta) on neutrophil elastase release. Inflammation 1995; 19: 83-99.

12. Larsson R, Rocksen D, Lilliehook B, Jonsson A, Bucht A. Dose-dependent activation of lymphocytes in endotoxin-induced airway inflammation. Infect Immun 2000; 68: 6962-6969.

13. Wang Z, Larsson K, Palmberg L, Malmberg P, Larsson $\mathrm{P}$, Larsson L. Inhalation of swine dust induces cytokine release in the upper and lower airways. Eur Respir J 1997; 10: 381-387.

14. Larsson BM, Palmberg L, Malmberg PO, Larsson K. Effect of exposure to swine dust on levels of IL-8 in airway lavage fluid. Thorax 1997; 52: 638-642.

15. Statement of the American Thoracic Society. Standardization of spirometry - 1987 update. Am Rev Respir Dis 1987; 136: 1285-1298.

16. Hedenstrom H, Malmberg P, Agarwal K. Reference values for lung function tests in females. Regression equations with smoking variables. Bull Eur Physiopathol Respir 1985; 21: 551-557.

17. Hedenstrom H, Malmberg P, Fridriksson HV. Reference values for lung function tests in men: regression equations with smoking variables. Ups $J$ Med Sci 1986; 91: 299-310.

18. Malmberg P, Larsson K, Thunberg S. Increased lung deposition and biological effect of methacholine by use of a drying device for bronchial provocation tests. Eur Respir J 1991; 4: 890-898.

19. Muller-Suur C, Larsson PH, Larsson K. T-cell activation by organic dust in vitro. Respir Med 2000; 94: 821-827. 